\title{
Impacts of photovoltaics on low voltage networks: A case study for the north west of England
}

DOI:

10.1049/cp.2013.1229

Link to publication record in Manchester Research Explorer

\section{Citation for published version (APA):}

Navarro, A., Ochoa, L. F., Mancarella, P., \& Randles, D. (2013). Impacts of photovoltaics on low voltage networks: A case study for the north west of England. In IET Conference Publications/IET Conf Publ (Vol. 2013) https://doi.org/10.1049/cp.2013.1229

\section{Published in:}

IET Conference Publications|IET Conf Publ

\section{Citing this paper}

Please note that where the full-text provided on Manchester Research Explorer is the Author Accepted Manuscript or Proof version this may differ from the final Published version. If citing, it is advised that you check and use the publisher's definitive version.

\section{General rights}

Copyright and moral rights for the publications made accessible in the Research Explorer are retained by the authors and/or other copyright owners and it is a condition of accessing publications that users recognise and abide by the legal requirements associated with these rights.

\section{Takedown policy}

If you believe that this document breaches copyright please refer to the University of Manchester's Takedown Procedures [http://man.ac.uk/04Y6Bo] or contact uml.scholarlycommunications@manchester.ac.uk providing relevant details, so we can investigate your claim.

\section{OPEN ACCESS}




\section{IMPACTS OF PHOTOVOLTAICS ON LOW VOLTAGE NETWORKS: A CASE STUDY FOR THE NORTH WEST OF ENGLAND}

\author{
Alejandro NAVARRO \\ University of Manchester - UK \\ alejandro.navarroespinosa@manchester.ac.uk \\ Pierluigi MANCARELLA \\ University of Manchester - UK \\ p.mancarella@manchester.ac.uk
}

\author{
Luis F. OCHOA \\ University of Manchester - UK \\ luis_ochoa@ieee.org \\ Dan RANDLES \\ Electricity North West Limited - UK \\ dan.randles@enwl.co.uk
}

\begin{abstract}
This work proposes a Monte Carlo-based technique to assess the impacts of different $P V$ penetrations on a real $L V$ network for the North West of England, considering 5-min resolution models for domestic load and $P V$ generation. The impacts of $P V$ location are analysed through two scenarios based on location: closer to and further from the distribution transformer. Voltage impacts are measured using EN50160 and the thermal capabilities are examined through a utilisation factor. Additionally, the effects of higher LV busbar voltages are also investigated. Results indicate that voltage issues are more constraining than asset utilisation, particularly with clusters closer to the transformer.
\end{abstract}

\section{INTRODUCTION}

The UK Government's Feed-in Tariff programme has already led to a total PV installed capacity exceeding $1.2 \mathrm{GW}$ [1], equivalent to $1.6 \%$ of the total installed generation capacity in Great Britain. More than $75 \%$ of this PV installed capacity comes from domestic installations, i.e., small-scale $(\leq 4 \mathrm{~kW})$ PV systems connected to the low voltage (LV) distribution networks. Although most LV networks have not yet seen high penetrations of PV systems, impacts such as voltage rise, thermal overloads, higher levels of imbalance, and higher levels of harmonics, etc. are expected as penetration increases [2], [3], [4].

To adequately assess the extent to which current LV networks can host future penetrations of small-scale PV systems without exceeding thermal limits of assets (lines or transformers) or statutory voltage limits, it is necessary to have realistic models. These models should take into account not only the three-phase construction of the LV circuits, but also the time dependency of single and threephase loads and PV generation along the day as well as the PV location and size.

High resolution models were applied in [5] to assess some of these impacts considering different penetrations levels (number of houses with generation) and unbalance three phase power flow analysis. However, the location and size of PV installations are considered deterministically. This approach is not always feasible given that in most instances DNOs do not know where PV systems will be installed. Due to this, in [6] it was proposed (but not developed) the use of Monte Carlo analysis to address the stochastic nature of the interaction between loads, networks and generation.

To tackle the uncertainty in the load profiles, PV profiles (including cloud transients) and PV size, a Monte Carlobased technique is developed in this work. This technique is applied to two different PV location scenarios in order to address the corresponding 'boundary' impacts. In the first one, the PV systems are located from the transformer to the last consumer (downstream), whereas in the second one they are located form the last consumer to the transformer (upstream). This approach allows investigating the 'boundary' scenarios in terms of location of PV clusters.

The methodology implemented is applied over one real LV networks in the North West of England considering 5-min resolution synthetic data for domestic load and PV generation. Different penetration levels (number of houses with PV systems) are modelled, ranging from 0 to $100 \%$ in each scenario. For each penetration level the voltage (based on the European Standard EN50160) and thermal impacts (based on asset utilisation) are assessed. The power flow simulations are solved by using an unbalanced three-phase load flow. The effects of higher LV busbar voltages are also investigated.

This work is structured as follows: section II explains the methodology. A real network application is presented in section III. Section IV summaries the LV busbar voltage analysis. Finally, conclusions are drawn in section V.

\section{METHODOLOGY}

First, load and PV profiles are created. These are then used in the proposed Monte Carlo framework.

\section{Creation of load Profiles}

To assess the performance of LV feeders, the time-series behaviour of loads and PV generation has to be modelled. This allows capturing the corresponding interactions that would otherwise be over or under-estimated by assuming worst case scenarios (e.g., min demand max generation). The residential profiles and the PV profiles used in this work have a resolution of five minutes, and have been produced using [7]. This tool takes into account the number of occupants, type of day (weekday or weekend), month, appliances, PV size and geographical location. Based on these parameters, it produces a load profile (appliances consumption) and a PV profile (considering cloud transients) as shown in Figure 1. These two profiles are linked by the corresponding sun irradiance, i.e., less irradiance means less PV production and probably higher lighting usage. 


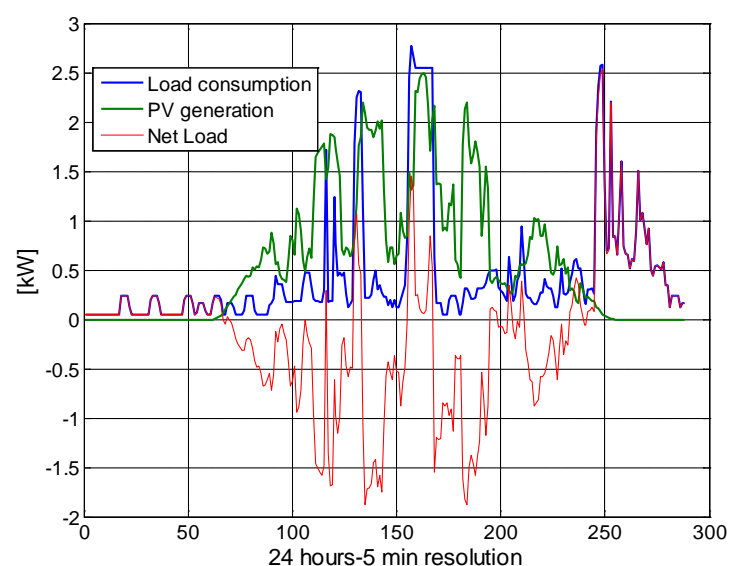

Figure 1. Example of load profile

This tool was automated in order to produce 2000 load profiles and $2000 \mathrm{PV}$ profiles to be used in the Monte Carlo approach. For simplicity, these profiles were created just for one weekday in September (sunny day). With the purpose of having a better representation of the UK profiles, the number of occupants to build the load profiles, and the PV system sizes to build the PV profiles is based on UK statistics. Thus, the proportion of houses with one person, two people, three people and four or more is 29, 35, 16 and 20\%, respectively [8]; and the proportion of PV systems with 1.0, 1.5, 2.0, 2.5, 3.0, 3.5 and $4 \mathrm{~kW}$ is $1,8,13,14,12$, and $37 \%$, respectively [1].

\section{Monte Carlo Approach}

Once, the load and PV profiles were created, it is possible to allocate them on the network and run power flow simulations for different penetration levels based on number of consumers/houses with PV (0 to $100 \%$ in steps of $10 \%)$. To address the stochastic nature of the problem, the following algorithm is proposed for each penetration level:

\section{Stage 1: Load Profile Selection}

For each single-phase consumer of the network, a load profile is randomly selected from the load profile pool. The corresponding PV profile (generated from the same sun radiance as the load profile) is also selected.

\section{Stage 2: PV Profile Allocation}

The PV profile associated with each consumer is 'activated' if the consumer has been allocated a PV system. To do this allocation, first the number of consumers with PV systems is determined according to the studied penetration level (i.e., 10\%). Then, consumers are allocated PV systems according to the scenario investigated.

1. Downstream. PV systems are successively allocated from the consumer closest to the transformer (first consumer) to the one furthest to the transformer until the studied penetration is reached.

2. Upstream. PV systems are successively allocated from the consumer furthest to the transformer to the one closest to the transformer (last consumer) until the studied penetration is reached.

\section{Stage 3: Impact analysis}

Once the load profiles and PV profiles are located, an unbalance three-phase time-series power flow is carried out. Each PV profile is modelled as a single-phase

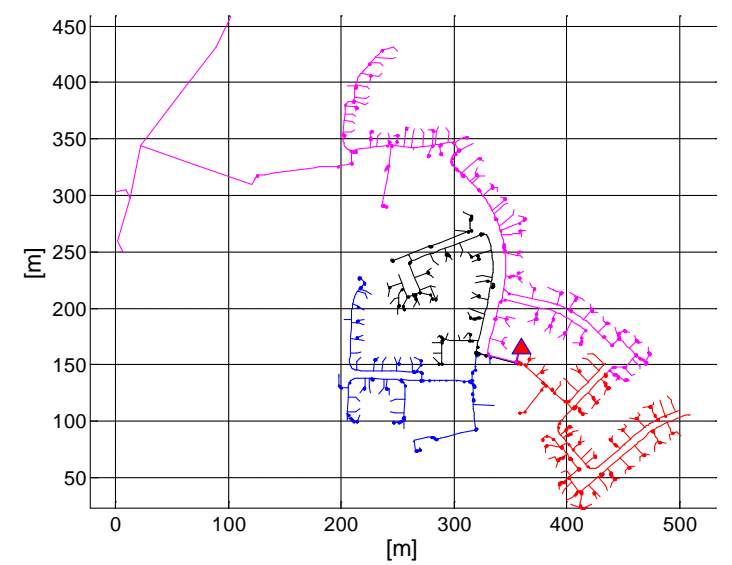

Figure 2. Network Topology

negative load with a power factor equal to unity. In this work, the voltage rise and the thermal capacity of the feeder (first line segment) are studied by using two indexes:

1. Percentage of consumers with voltage problems. It checks whether the voltages calculated at the singlephase connection point of each consumer from the time-series power flow simulations satisfy the European Standard EN50160 [9]. Here the standard, that considers 10 minute averages during a week, is limited to only one day. Consumers with voltage issues are counted and the corresponding percentage calculated.

2. Utilisation factor of the main feeder. Calculated as the hourly maximum current through the main segment of the feeder divided by its corresponding ampacity. The current is obtained by averaging the results from the 5-min power flow simulations within each hour. This index aims to show how asset utilisation behaves with different PV penetration levels.

Finally, the stages 1 to 3 are repeated hundreds of times for each penetration level and for each network feeder for the two allocation scenarios. Thus, it is possible to find the boundaries for the proposed indexes.

\section{REAL NETWORK APPLICATION}

The proposed methodology has been applied to one real network located in the North West of England, owned and operated by Electricity North West Limited (ENWL). This network was fully modelled taking into account the network topology (GIS data), conductor characteristics (three-phase four-wire), consumer locations and phase connectivity.

The network used is shown in Figure 2, each colour represents a different feeder and the red triangle indicates the substation location. The length and the number of consumers per feeder are presented in Table 1.

The power flow simulations are solved feeder by feeder using OpenDSS [10] and a fixed line-to-neutral voltage of $240 \mathrm{~V}$ at the secondary of the transformer is assumed. In particular, the results for feeder 1 (purple in Figure 2) are shown in Figure 3 and Figure 4 and the summary for every feeder is presented in Table 1.

Given the Monte Carlo analysis, it is possible to show in Figure 3 and Figure 4 the average value and its standard 


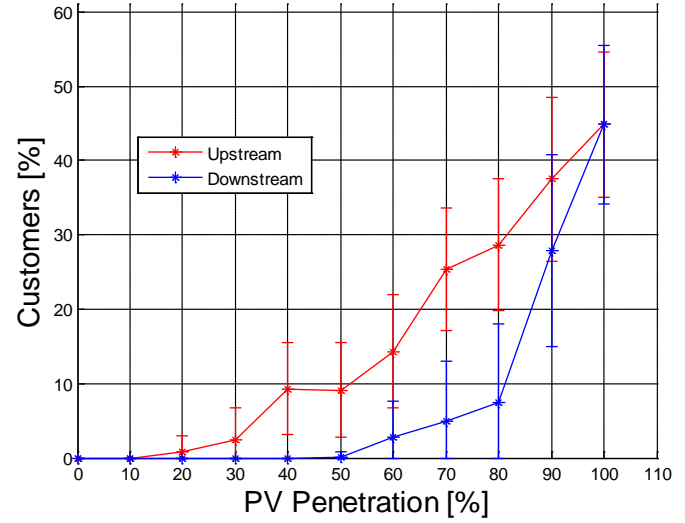

Figure 3. Consumers with voltage issues - Feeder 1

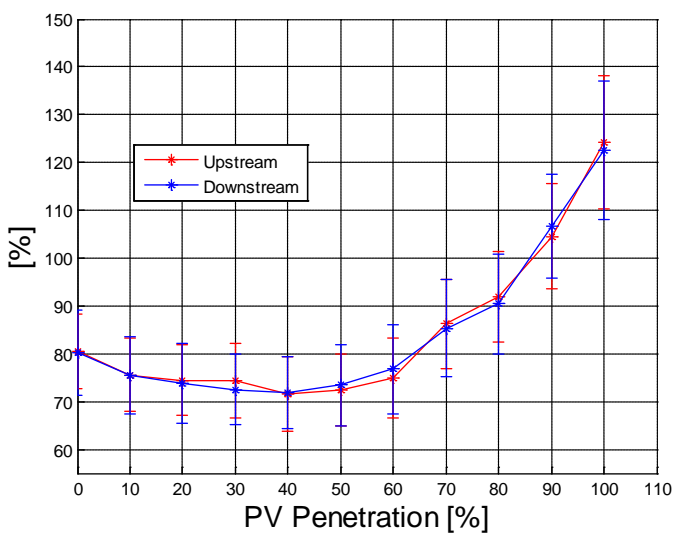

Figure 4. Utilisation level of the first line segment - Feeder 1

Table 1. PV penetration leading to voltage or utilisation issues

\begin{tabular}{c|c|c|c|c}
\hline Feeder & $\begin{array}{c}\mathbf{1} \\
\text { Purple }\end{array}$ & $\begin{array}{c}\mathbf{2} \\
\text { Black }\end{array}$ & $\begin{array}{c}3 \\
\text { Blue }\end{array}$ & $\begin{array}{c}\mathbf{4} \\
\text { Red }\end{array}$ \\
\hline Distance (m) & 2291 & 868 & 920 & 1289 \\
\hline No. of Consumers & 70 & 31 & 26 & 53 \\
\hline Voltage Problems - Downstream & $60 \%$ & $90 \%$ & No & $90 \%$ \\
\hline Voltage Problems - Upstream & $20 \%$ & $60 \%$ & No & $40 \%$ \\
\hline Utilisation >80\% - Downstream & $80 \%$ & No & No & $90 \%$ \\
\hline Utilisation > 80\% - Upstream & $80 \%$ & No & No & $90 \%$ \\
\hline
\end{tabular}

deviation for the one hundred simulations executed for each penetration level (for the studied sunny day).

Figure 3 clearly indicates the range of impacts between the downstream and upstream PV allocation. For instance, at $70 \%$ of penetration level the consumers with problems are below $5 \%$ and about $30 \%$ for the downstream and upstream case, respectively. The downstream case presents the first consumers with problems at $60 \%$ of penetration level, whereas they appear at $20 \%$ of penetration level for the upstream case. Figure 4 gives a good idea about how the feeder is utilised for the different penetration levels. As expected, there is little difference between the allocation scenarios. The main outcome of this figure is the classic $U$ characteristic. With no PV systems the average utilisation level is about $80 \%$. It decreases with more PV systems. This means that the local generation is to some extent supplying the household demand and that reverse power flows (if any) are below the no PV scenario. This trend

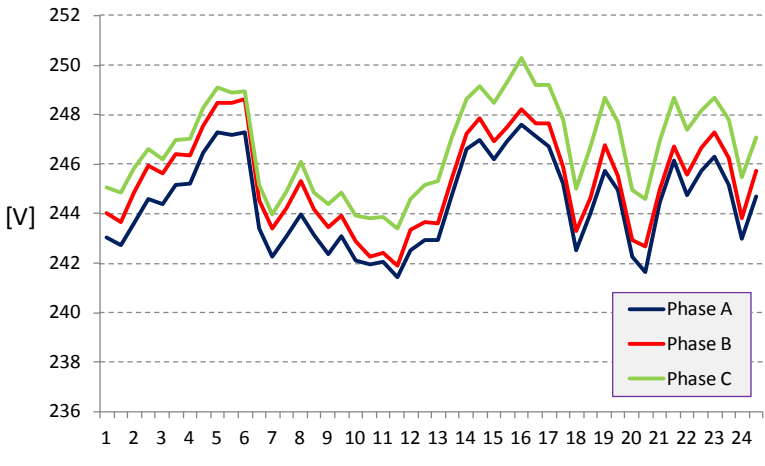

24 hours - 5 min resolution

Figure 5. Voltage at the transformer secondary - Measured data

ends with a PV penetration of $40 \%$ for the downstream and upstream case. After that point, the utilisation level starts to increase with more PV installations. With 70\% of penetration the utilisation level exceeded the same value as without PV; this means that reverse power flows are larger than the original feeder consumption. The maximum capacity is surpassed with $90 \%$ penetration.

The results for every feeder and for both allocation scenarios are summarised in Table 1. The row "Voltage Problems" refers to the PV penetration level in which consumers start having voltage issues for the downstream and upstream cases. The row "Utilisation Level" indicates the PV penetration level that results in utilisation bigger than $80 \%$ for the downstream and upstream cases. This value was adopted to show potential limitations in headroom capacity for operational tasks. Table 1 indicates that the longer and more loaded feeders present voltage issues before.

It is also important to observe that until $20 \%$ of penetration level there are no consumers with voltage problems in any of the feeders studied.

\section{BUSBAR VOLTAGE ANALYSIS}

In the previous analysis, a fixed line-to-neutral $240 \mathrm{~V}$ at the secondary of the transformer was assumed. However, in reality this value changes from one transformer to another (different off load tap position) and also during the day because of the load variation upstream and downstream of the transformer. For example, Figure 5 shows real data for the LV busbar voltage of one ENWL network. This data comes from the ongoing project "Low Voltage Network Solutions" [11]. This is typical of UK DNO practice where sending voltage is often set high to aid voltage regulation.

For the particular day shown in Figure 5, it is possible to observe that the voltage is within 242 and $250 \mathrm{~V}$. Consequently, to analyse the effects of busbar voltages higher than 240V (adopted previously), the complete process presented in the previous section was executed again considering a fixed value of $250 \mathrm{~V}$.

To facilitate the comparison, this new analysis is presented for the same example feeder (purple in Figure 2) and only the average values for one hundred simulations are presented.

Clearly, a much higher busbar voltage does not produce significant differences in the utilisation level (Figure 7). However, the differences in consumers with voltage 


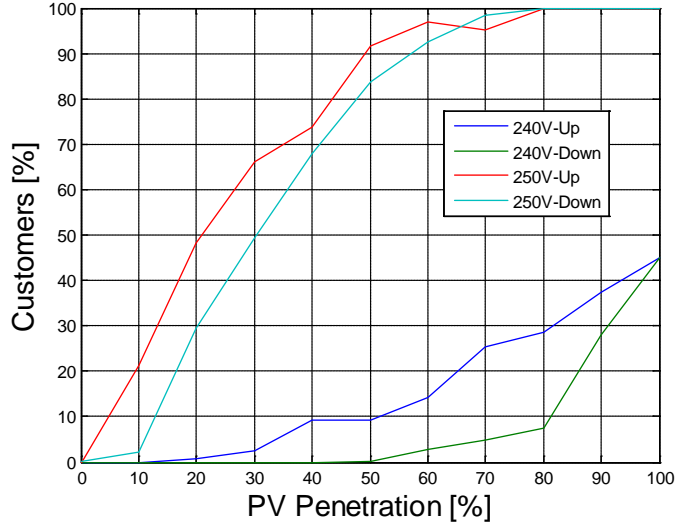

Figure 6. Consumers with Voltage Problems - Comparison

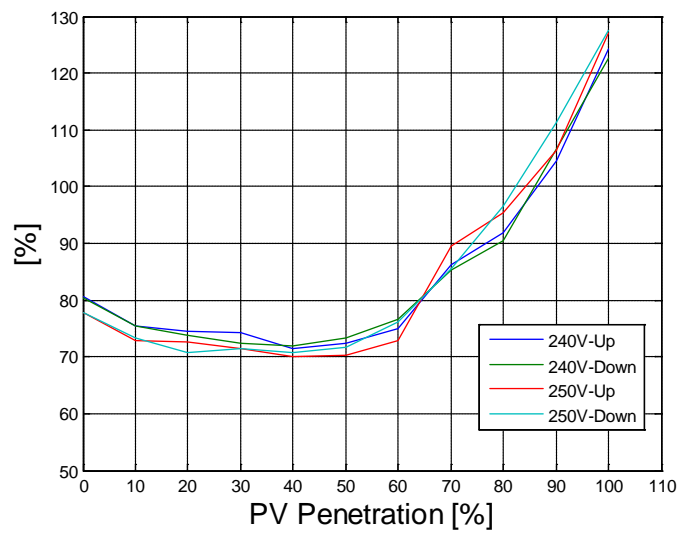

Figure 7. Utilisation Level - Comparison

problems are much more significant (Figure 6). In fact, using $250 \mathrm{~V}$ the range between the upstream and downstream case decreases and also the problems start earlier, at $10 \%$ of penetration level.

\section{CONCLUSIONS}

This work presented a Monte Carlo-based assessment of impacts from residential PV generation on a real LV network for the North West of England. The location of PV systems was considered from two 'boundary' perspectives: one where they are located from the transformer to the last consumer (downstream) and another where they located form the last consumer to the transformer (upstream). Five-minute resolution data for load and generation profiles were used. For each penetration level (based on number of consumers) and corresponding Monte Carlo simulation, the impacts on voltages (considering the European Standard EN50160) and asset utilisation were calculated.

The results for the studied network indicate, as expected, that PV location plays a significant role on the potential impacts on voltage. In addition, it was also observed that longer feeders present voltage issues sooner than shorter ones. Moreover, for this particular case study, there were no impacts for penetration levels up to $20 \%$ (although this becomes $10 \%$ with a higher busbar voltage).

The analysis of the effects of higher busbar voltages also highlighted that networks with higher tap position will pose a significant constraint for the connection of PV systems. Changing fixed tap positions, however, might not necessarily be the solution as peak load (evening) will not be coincident with PV generation.

\section{ACKNOWLEDGMENTS}

This work has partly been funded by Electricity North West Limited (ENWL), UK, through the Ofgem's Low Carbon Networks Fund Tier 1 Project "LV Network Solutions", 2011-2014.

The authors would like to thank the support of ENWL for the funding and making available the network data. Also to the Centre for Renewable Energy Systems Technology (CREST) at Loughborough University, UK, for making available the load and PV generation models used here.

\section{REFERENCES}

[1] UK Department of Energy and Climate Change (DECC), "Weekly solar PV installation and capacity," August, 2012.

[2] M. Begovic, I. Kim, D. Novosel, J. R. Aguero, and A. Rohatgi, "Integration of photovoltaic distributed generation in the power distribution grid," in Proc. 2011, pp. 1977-1986.

[3] R. A. Walling, R. Saint, R. C. Dugan, J. Burke, and L. A. Kojovic, "Summary of distributed resources impact on power delivery systems," IEEE Transactions on Power Delivery, vol. 23, no. 3, pp. 1636-1644, 2008.

[4] L. F. Ochoa and P. Mancarella, "Low-carbon LV networks: Planning and operation challenges," in Proc. 2012 IEEE/PES General Meeting 2012, pp. 2.

[5] M. Thomson and D. G. Infield, "Impact of widespread photovoltaics generation on distribution systems," IET Renewable Power Generation, vol. 1, no. 1, pp. 33-40, 2007.

[6] M. M. Begovic and I. Kim, "Distributed renewable PV generation in urban distribution networks," in Proc. 2011.

[7] I. Richardson and M. Thomson, "Domestic Electricity Demand Model-Integrated Domestic Electricity Demand and PV Micro- generation Model," Loughborough University Institutional Repository, http://hdl.handle.net/2134/7773, 2010.

[8] Office for National Statistics, "Families and households, 2001 to 2011," Statistical Bulletin, January 2012.

[9] British Standards Institution, "BS EN 50160: Voltage characteristics of electricity supplied by public distribution systems," 2000.

[10] EPRI, "Open Distribution System Simulator [Online]," Available: http://sourceforge.net/apps/mediawiki/electricdss.

[11] Ofgem. (2013, (January 2013). Electricity North West Limited Tier 1 Low Carbon Networks Fund Projects. [Online]. Available: http://www.ofgem.gov.uk/Networks/ElecDist/lcnf/ft p/enwl/Pages/index.aspx 